\title{
Comparison of the Datar-Mathews Method and the Fuzzy Pay-Off Method through Numerical Results
}

\author{
Mariia Kozlova, Mikael Collan, and Pasi Luukka \\ School of Business and Management, Lappeenranta University of Technology, Lappeenranta, Finland \\ Correspondence should be addressed to Mariia Kozlova; mariia.kozlova@lut.fi
}

Received 22 June 2016; Accepted 25 September 2016

Academic Editor: Panos Pardalos

Copyright ( 2016 Mariia Kozlova et al. This is an open access article distributed under the Creative Commons Attribution License, which permits unrestricted use, distribution, and reproduction in any medium, provided the original work is properly cited.

\begin{abstract}
The paper compares numerically the results from two real option valuation methods, the Datar-Mathews method and the fuzzy payoff method. Datar-Mathews method is based on using Monte Carlo simulation within a probabilistic valuation framework, while the fuzzy pay-off method relies on modeling the real option valuation by using fuzzy numbers in a possibilistic space. The results show that real option valuation results from the two methods seem to be consistent with each other. The fuzzy pay-off method is more robust and is also usable when not enough information is available for a construction of a simulation model.
\end{abstract}

\section{Introduction}

Real option analysis (ROA) is slowly becoming a part of the investment analysis process in companies [1-3], while it has been gaining more and more attention in academia. The reason for excitement around ROA is that it offers the ability to better incorporate uncertainty and to capture the value of managerial flexibility when the profitability of investments is analyzed [4,5]. The first models used for numerical real option valuation were models that had been originally designed for the valuation of financial options, namely, the Black-Scholes formula [6] and binomial option pricing techniques [7]. These models are still used for a range of valuation problems [8-10]. Later, a number of new real option valuation models with various model-constructs and modeling choices have emerged [11]. There seems to be a migration by business users of real option analysis away from using the "old" models designed originally for financial option valuation towards the use of simulation-based (Monte Carlo) ROV methods [1218], fuzzy real option valuation [19-26], and models that use system dynamic modeling as the basis for framing the real option analysis [27-30]. The different ROA methods are not necessarily competitors to each other, as the selection of the model used should be made based on the type of uncertainty that surrounds the analyzed investment and hence based on the type of the available information [31].
This paper concentrates on comparatively numerically analyzing two ROA methods, the Datar-Mathews method (DMM) that exploits Monte Carlo simulation in real option valuation [12-14] and the fuzzy pay-off method (FPOM) that is based on using managerially estimated cash-flow scenarios represented as fuzzy numbers as the basis for real option valuation [19-22]. Both methods have similar real option valuation logic [31] but are based on a different set of modeling choices. The Datar-Mathews method is usable under the assumption that there is enough information available for the construction of a credible model to underlie a Monte Carlo simulation, while the fuzzy pay-off method is usable also in situations where only information that is in the form of expert estimates about future cash-flows is available.

This research, of which initial ideas are reported in [32], presents the comparison of these two methods by investigating the difference between the final resulting real option values and by studying the generated distributions used in these two methods. Comparison of the (mathematical) structure of the two methods is left outside the scope of this paper. Two investment cases are used in the analysis; both are based on a solar photovoltaic power generation investment but under two different regimes of support mechanism for the investment. This paper continues in vein with other recent researches on the usability of the fuzzy pay-off method as a tool for real option valuation; see [33]. 
This paper continues by presenting the constructs of the Datar-Mathews method and of the fuzzy pay-off method, followed by two case-based numerical illustrations that are used to showcase the practical use of the methods. Then, the results from the numerical illustrations are compared and finally the paper is closed with a discussion and conclusions.

\section{The Two Methods Shortly Presented}

In this part, we describe the structures of the two compared ROA methods, the Datar-Mathews method and the fuzzy pay-off method.

2.1. The Datar-Mathews Method. Datar-Mathews real option valuation method [12] (DMM) is based on using Monte Carlo simulation to capture the uncertainty found in investments projects. Typically, when the method is used, a net present value profitability analysis model is used. It is often the case that businesses have such a model already in place and it can be used as a starting point for the Datar-Mathews ROA. The model construct typically includes the important profitability-affecting variables for the costs and for the revenues that together form the basis for calculating yearly cost and revenue cash-flows from an investment project. The yearly cost and revenue cash-flows are discounted by using separate discount rates, typically one for the costs and one for the revenues. The idea with using separate cash-flows is that the cost and the revenue cash-flow "processes" are not the same and that their risk levels are different. The DatarMathews ROV procedure includes the following steps (we assume that a calculation model is in place):

(1) Managers are asked to define the type and details of the distribution of the possible values for each model input variable, from which the simulation procedure randomly draws values.

(2) Simulation is run to generate a sufficient number of (typically thousands) pseudorandom profitability (NPV) outcomes with the model. From the outcomes a histogram is compiled, which is treated as a probability distribution of the project NPV pay-off.

(3) The DMM treats the project as an option and in order to "move" from the NPV pay-off distribution to an option pay-off distribution the subzero outcomes from the project are mapped to zero, while they keep their original probability weight. This means that all the negative outcomes' weights are truncated to zero.

(4) The real option value (ROV) is calculated as the mean of the resulting option pay-off distribution.

Under these circumstances, the real option value of the project can be formulated as [12]

$$
\begin{aligned}
& \text { “Risk Adjusted Success Probability } \\
& \quad \times \text { (Benefits - Costs).” }
\end{aligned}
$$

The Datar-Mathews method is a relatively simple method for the user. In addition to the needed discounted cashflow the user must have the ability to use a standard Monte
Carlo simulation. Typically the analysis is conducted on spreadsheet software. The method has previously been used, for example, in the valuation of aircraft development projects $[12,13,34]$, analysis of prognostic technology in health management [35], and the evaluation of renewable energy projects [36].

2.2. Fuzzy Pay-Off Method. Fuzzy pay-off method [19] (FPOM) is based on using managerially given cash-flow scenarios that typically consist of yearly cash-flow estimates from a project as the starting point. The estimated cash-flows are used in an NPV valuation of each scenario. From the scenario NPVs a fuzzy number pay-off distribution for the project is generated. From the created fuzzy pay-off distribution the project real option value is calculated. The procedure used in the fuzzy pay-off method can be expressed shortly as follows:

(1) Three or four scenarios of the future project cashflow streams are estimated. Typically the managers are asked to provide estimates for a "minimum possible" and a "maximum possible" and one or two "best estimate" scenarios. The estimated cash-flows are used in the calculation of the NPV for each scenario. Revenues and costs may be estimated separately and separate discount rates may be used for revenues and costs. The link between the operational costs and the revenues must be properly scrutinized; see [20].

(2) A fuzzy pay-off distribution for the project is constructed from the scenario NPVs. As three or four scenarios are typically used, the fuzzy pay-off distribution is either triangular or trapezoidal. The minimum possible and maximum possible scenario NPVs are considered to establish the lower and the upper limits of the distribution and they are assigned a limit to zero degree of membership in the set of possible NPV outcomes. The best estimate value(s) is assigned full membership.

(3) The real option value is directly calculated from the fuzzy pay-off distribution. The formula used adheres to the typical real option valuation logic and is simply the possibilistic mean of the positive side of the distribution weighted by the project "success ratio." The project success ratio is the area of the pay-off distribution over the positive side divided by the total area of the pay-off distribution; see the following equation:

$$
\mathrm{ROV}=E\left(A^{+}\right) * \frac{A^{+}}{A}
$$

Details of the fuzzy pay-off method can be found in [19], while the original resource for the possibilistic mean used is given in [37]. What can be said about the procedure used when using the method is that it is simple and the computational procedure does not require "any" computing power. The fuzzy pay-off method has been applied to several realword problems, including the analysis and selection of $R \& D$ projects $[38,39]$, the analysis of large industrial investments $[25,40]$, and patent valuation [24]. 
TABLE 1: Uncertain factors: see [31] for details.

\begin{tabular}{lccc}
\hline Factor & \multicolumn{3}{c}{ Range of values } \\
& Pessimistic & Best estimate & Optimistic \\
\hline $\begin{array}{l}\text { Electricity price, } \\
\text { rub./MWh }\end{array}$ & 1000 & 2000 & 3000 \\
$\begin{array}{l}\text { Consumer price index } \\
\text { (inflation) }\end{array}$ & 1.70 & 1.35 & 1.00 \\
$\begin{array}{l}\text { CapEx level } \\
\begin{array}{l}\text { Capacity factor (percent } \\
\text { of target) }\end{array}\end{array}$ & $150 \%$ & $100 \%$ & $80 \%$ \\
$\begin{array}{l}\text { Localization } \\
\text { requirement }\end{array}$ & Failed & Fulfilled & Fulfilled \\
\hline
\end{tabular}

\section{Numerical Case-Based Illustration of the Two Methods and Comparison of the Results}

Two investment cases are used to compare results derived with the two methods. The investment cases are both industrial-scale investment projects into a solar photovoltaic (PV) power plant but under different renewable energy supporting schemes (subsidy schemes).

The first case analyzes an investment that falls within the scope of the Russian renewable energy (RE) support mechanism, based on long-term capacity contracts with a rather complex incentive system. A guaranteed capacity price within these contracts is calculated by the regulating authority as a variable rate annuity that is designed to provide a certain level of return on investment. The scheme takes into account changing market conditions and the project-specific performance $[41,42]$. For more information about the Russian RE investment incentive mechanisms, see [43-46].

The second case represents an investment into the same project under a simpler generic feed-in premium RE incentive scheme, such as that which is used more generally in Europe. The used incentive scheme guarantees a fixed premium over the spot electricity price over the long term (for the calculations twenty years are assumed). For the purposes of this illustration, the premium level is set in a way that it provides approximately the same level of profitability as the first case. This has no importance for the comparison of the results from the point of view of the comparative analysis of the two real option analysis methods but allows the comparison of the two RE incentive mechanisms for those interested. A more detailed description of the two cases and the set of assumptions made can be found in [36].

A typical "classical" NPV investment profitability analysis calculation model is used in both cases. The software used is Microsoft Excel ${ }^{\circledR}$ for the analyses with the fuzzy pay-off method and Matlab Simulink ${ }^{\circledR}$ for the analyses with the Datar-Mathews method. Even if the software used to run the analysis is different, the models used are identical. The information used in creating the three needed scenarios for the fuzzy pay-off method is presented in Table 1.

The same values (Table 1) are also used as the basis for the pseudorandom distribution, from which the Monte Carlo
TABLE 2: Comparison of result statistics (in rub. bln.).

\begin{tabular}{|c|c|c|c|c|c|c|}
\hline & \multicolumn{3}{|c|}{ First case } & \multicolumn{3}{|c|}{ Second case } \\
\hline & DMM & FPOM & Difference & DMM & FPOM & Difference \\
\hline ROV & 0.004 & 0.002 & 0.002 & 0.022 & 0.021 & 0.001 \\
\hline$E(\mathrm{NPV})$ & -0.525 & -0.261 & 0.264 & -0.322 & -0.217 & 0.105 \\
\hline $\begin{array}{l}\text { Standard } \\
\text { deviation } \\
(\times 100 \%)\end{array}$ & 0.441 & 0.358 & 0.083 & 0.384 & 0.406 & 0.022 \\
\hline $\begin{array}{l}\text { "Success } \\
\text { ratio" }\end{array}$ & $3 \%$ & $9 \%$ & $6 \%$ & $11 \%$ & $28 \%$ & $17 \%$ \\
\hline
\end{tabular}

simulation used in the Datar-Mathews method draws the random outcomes for these variables. Uniform distributions between the "pessimistic" and "optimistic" values are used in the illustration. One hundred thousand rounds of simulation are run for both cases. In the generic feed-in premium case, the "localization requirement" variable is not used.

3.1. Numerical Results of the Two Cases and a Comparison of the Methods Based on the Results. Results for the first case with the two methods are presented in Figure 1. Figure 1(a) shows a histogram that has been generated from the results of the Monte Carlo simulation used in the Datar-Mathews method; the expected NPV and ROV are shown with dashed lines. Figure 1(b) shows the triangular NPV distribution constructed when using the fuzzy pay-off method with the expected NPV and the calculated ROV values. Figure 1(c) shows a stylized overlap of the two graphs.

One can observe that the lowest and the highest values of the distributions match, which is expected, but in this case the shapes of the two distributions are very different. The rather complex construct of the underlying Russian RE incentive mechanism causes the shape of the simulated NPV pay-off histogram of the project to be atypical with multiple summits. This indicates that there are local maxima which the Monte Carlo simulation used in the Datar-Mathews method can capture. At the same time, it is quite clear that the fuzzy pay-off method may be too robust for the complex problem. What is interesting is that the real option valuation results are nevertheless similar in absolute numbers; see also Table 2.

Results for the second case, an investment into a renewable energy project with a generic feed-in premium incentive system, are presented in Figure 2. In Figure 2(a), the histogram generated from the results of the Monte Carlo simulation for the Datar-Mathews method is visible. Again the expected (single number) NPV and the ROV are shown as dashed lines. The shape of the simulated distribution is more "typical" as there are no "conditioning" variables that would cause the distribution to exhibit multiple summits. Figure 2(b) exhibits the triangular distribution constructed with the fuzzy pay-off method and Figure 2(c) shows a stylized overlap of the two graphs.

As in the first case, the "limits" or the extreme high and low values of the distributions are almost equal; again this was expected; however, the shapes of the two distributions are much more uniform compared to the first case. This can be interpreted in the way that the problem complexity 


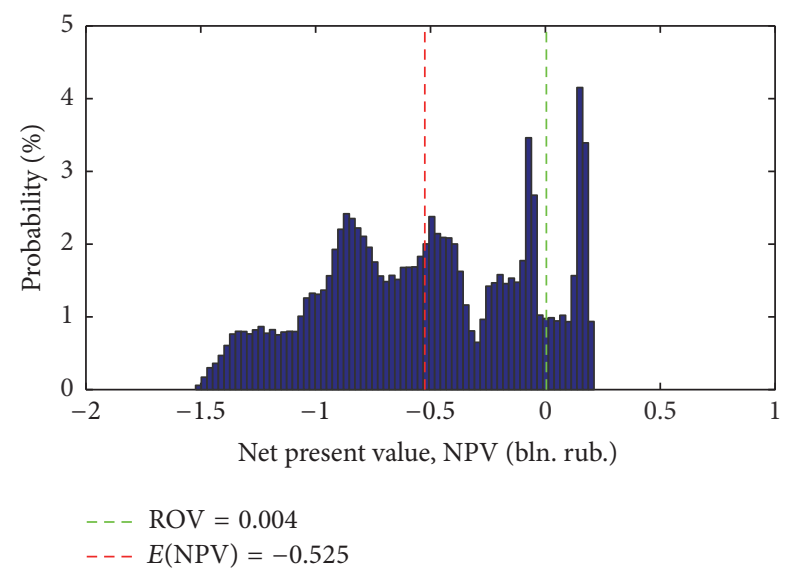

(a)

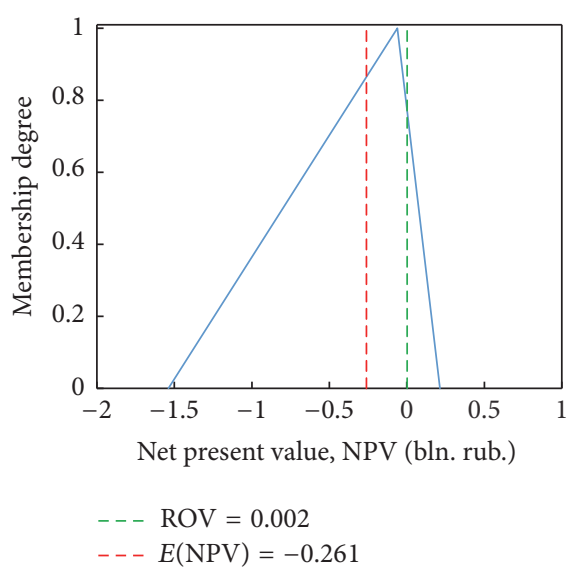

(b)

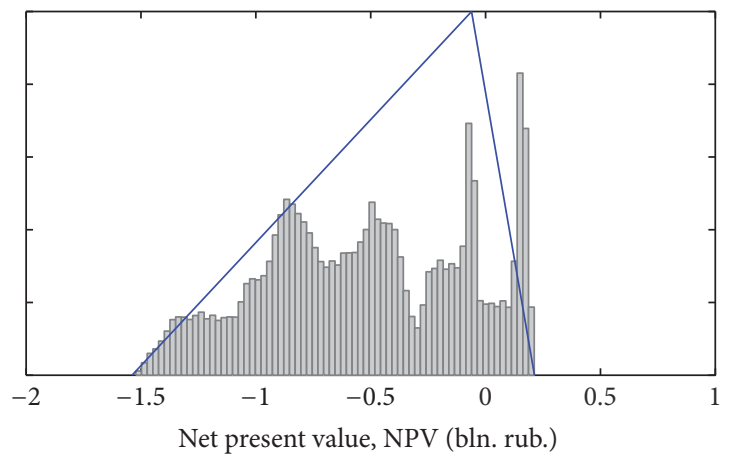

(c)

FIGURE 1: NPV distributions for the first case. (a) Simulated NPV distribution, (b) triangular fuzzy NPV, and (c) stylized plot of both distributions on the same graph. Dashed lines: red, expected NPV; green, ROV.

is at a level that is suitable also for the more robust fuzzy pay-off method. The results from the two methods are more similar to each other in the second case than in the first case; this indicates that when the type of problem analyzed is relatively simple the precision of the fuzzy pay-off method can be considered to be satisficing. The difference between the $\mathrm{ROV}$ in the second case is negligible. Lilliefors test shows that the simulated distributions in both cases are not "normal." Descriptive statistics for the two cases are collected in Table 2 for easy comparison.

Table 2 clearly shows that the results from the two methods are not equal. It would have been very surprising if they were, as the construct and the degree of simplification are different. What can be however seen is that the results, especially for the ROV, are surprisingly similar in both cases. Otherwise, the descriptive statistics for the second case are more similar between the two methods; this can be attributed to the simpler problem structure.

Despite the comparable numeric indicators, the DMM and the FPOM are substantially different in terms of their implementation and computational performance (Table 3).

The computational time to run both analyses is short, but the simulation used in the DMM is time-consuming; it takes roughly 25-50 times more time than running three scenario calculations for the FPOM. The simulation time depends on the complexity of the problem. In addition, implementing
TABLE 3: Comparison of DMM and FPOM performances.

\begin{tabular}{|c|c|c|}
\hline & DMM & FPOM \\
\hline $\begin{array}{l}\text { Computational } \\
\text { time (first case), s. }\end{array}$ & 6.19 & 0.11 \\
\hline $\begin{array}{l}\text { Computational } \\
\text { time (second case), } \\
\text { s. }\end{array}$ & 1.01 & 0.04 \\
\hline $\begin{array}{l}\text { Ease of } \\
\text { implementation }\end{array}$ & $\begin{array}{l}\text { Requires simulation } \\
\text { software and the skills } \\
\text { to use it }\end{array}$ & $\begin{array}{l}\text { Simple spreadsheet } \\
\text { software is enough }\end{array}$ \\
\hline $\begin{array}{l}\text { Information } \\
\text { content of results }\end{array}$ & $\begin{array}{l}\text { Histogram of the } \\
\text { outcome, ability to } \\
\text { capture irregularities } \\
\text { of complex problems, } \\
\text { for example, } \\
\text { step-causal or } \\
\text { nonlinear } \\
\text { interdependency of } \\
\text { variables }\end{array}$ & $\begin{array}{l}\text { A triangular pay-off } \\
\text { distribution has a } \\
\text { fixed form regardless } \\
\text { of the problem } \\
\text { complexity, a } \\
\text { simplification of } \\
\text { results }\end{array}$ \\
\hline
\end{tabular}

the DMM requires building a model in a computational environment with Monte Carlo simulation capability and requires the user of the model to have the required skills to build simulation models and to run them. In contrast, the 


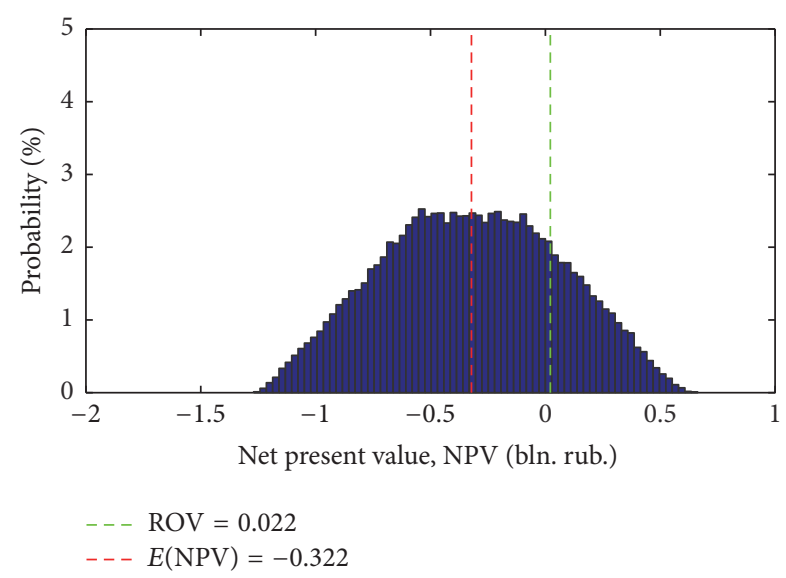

(a)

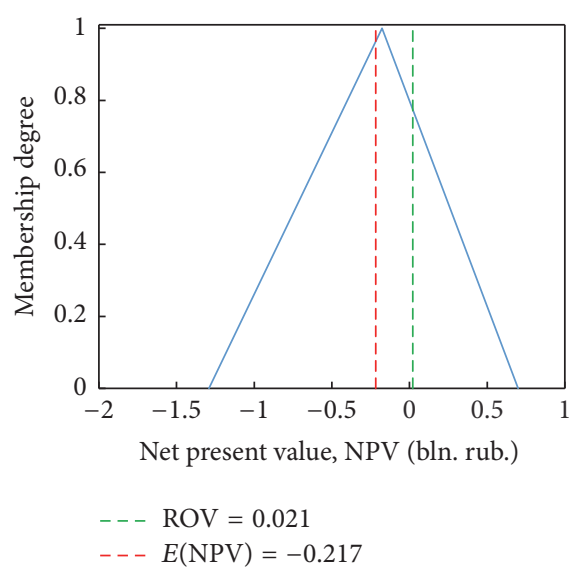

(b)

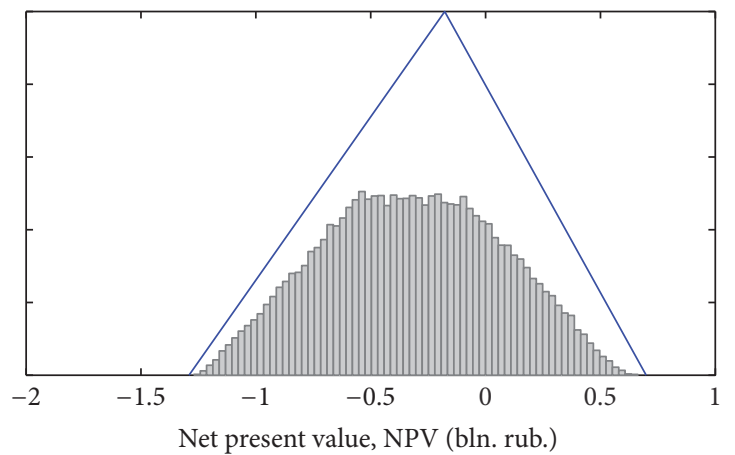

(c)

FIGURE 2: NPV distributions for the second case. (a) Simulated NPV distribution, (b) triangular fuzzy NPV, and (c) stylized plot of both distributions on the same graph. Dashed lines: red, expected NPV; green, ROV.

FPOM can be easily implemented with spreadsheet software, without any special skills.

The findings presented here support the previous findings [33] on the practical usability of the fuzzy pay-off method when the type of information available and the problem structure are robust.

\section{Conclusions}

The Datar-Mathews and the fuzzy pay-off method are both relatively new real option analysis methods that have been constructed, while keeping in mind managerial users. Both exploit the well-known real option valuation logic but are based on different theoretical foundations in terms of their computational procedure. The Datar-Mathews method is a simulation-based method that treats uncertainty in terms of probability theory, while the fuzzy pay-off method is a more robust method based on using fuzzy number representations of cash-flow information.

This paper has demonstrated with numerical illustrations the application and usability of these two methods in the analysis of two investment cases with different levels of complexity. The comparative analysis of the results of these analyses reveals that while the pay-off method simplifies the analysis, it still seems to offer sufficient precision for the analysis of problems with low complexity. On the other hand, the simulation-based Datar-Mathews method is able to treat problems that have more complex structures but requires more computational time and specialized software. The overall results obtained in terms of real option valuation show that the two methods return similar results. One has to observe that the two presented cases are not enough to draw definitive conclusions on the matter but illustrate well the difference in how robust these methods are.

The work presented in this paper can be used in understanding better the kinds of problems these methods are good for. The results are of use for practitioners navigating selection of proper valuation technique and support earlier findings on the usability of these methods. The comparison of these methods with other methods merits further study and specifically the amount of complexity and type of uncertainty that different methods can handle in terms of credible and usable results. In more general terms, the study of the usability of different analysis real option analysis methods is a topic that has been "under studied" in the past.

\section{Competing Interests}

The authors declare that there are no competing interests regarding the publication of this paper. 


\section{Acknowledgments}

The authors would like to acknowledge the support received by Mariia Kozlova from Fortum Foundation.

\section{References}

[1] P. A. Ryan and G. P. Ryan, "Capital budgeting practices of the Fortune 1000: how have things changed," Journal of Business and Management, vol. 8, no. 4, pp. 355-364, 2002.

[2] S. Block, "Are 'real options' actually used in the real world?" The Engineering Economist, vol. 52, no. 3, pp. 255-267, 2007.

[3] J. R. Graham and C. R. Harvey, "The theory and practice of corporate finance: evidence from the field," Journal of Financial Economics, vol. 60, no. 2-3, pp. 187-243, 2001.

[4] L. Trigeorgis, Real Options: An Overview, Praeger, Westport, Conn, USA, 1995.

[5] M. Amram and N. Kulatilaka, Real Options: Managing Strategic Investment in an Uncertain World, Oxford University Press, New York, NY, USA, 1998.

[6] F. Black and M. Scholes, "The pricing of options and corporate liabilities," The Journal of Political Economy, vol. 81, no. 3, pp. 637-654, 1973.

[7] J. C. Cox, S. A. Ross, and M. Rubinstein, "Option pricing: a simplified approach," Journal of Financial Economics, vol. 7, no. 3, pp. 229-263, 1979.

[8] A. A. Gray, P. Arabshahi, E. Lamassoure, C. Okino, and J. Andringa, "A real options framework for space mission design," in Proceedings of the IEEE Aerospace Conference, pp. 137-146, IEEE, Big Sky, Mont, USA, March 2005.

[9] B. Kim, H. Lim, H. Kim, and T. Hong, "Determining the value of governmental subsidies for the installation of clean energy systems using real options," Journal of Construction Engineering and Management, vol. 138, no. 3, pp. 422-430, 2012.

[10] S. L. MacDougall, "The value of delay in tidal energy development," Energy Policy, vol. 87, pp. 438-446, 2015.

[11] L. Trigeorgis, Real Options: Managerial Flexibility and Strategy in Resource Allocation, MIT Press, Boston, Mass, USA, 1996.

[12] S. Mathews, V. Datar, and B. Johnson, "A practical method for valuing real options: the boeing approach," Journal of Applied Corporate Finance, vol. 19, no. 2, pp. 95-104, 2007.

[13] S. Mathews and J. Salmon, "Business engineering: a practical approach to valuing high-risk, highreturn projects using real options," in Tutorials in Operations Research, chapter 9, pp. 157175, 2007.

[14] V. T. Datar and S. H. Mathews, "European real options: an intuitive algorithm for the Black-Scholes formula," Journal of Applied Finance, vol. 14, pp. 45-51, 2004.

[15] C. Bastian-Pinto, L. Brandão, and W. J. Hahn, "Flexibility as a source of value in the production of alternative fuels: the ethanol case," Energy Economics, vol. 31, no. 3, pp. 411-422, 2009.

[16] T. K. Boomsma, N. Meade, and S.-E. Fleten, "Renewable energy investments under different support schemes: a real options approach," European Journal of Operational Research, vol. 220, no. 1, pp. 225-237, 2012.

[17] M. Monjas-Barroso and J. Balibrea-Iniesta, "Valuation of projects for power generation with renewable energy: a comparative study based on real regulatory options," Energy Policy, vol. 55, pp. 335-352, 2013.

[18] W. H. Reuter, S. Fuss, J. Szolgayová, and M. Obersteiner, "Investment in wind power and pumped storage in a real options model," Renewable and Sustainable Energy Reviews, vol. 16, no. 4, pp. 2242-2248, 2012.

[19] M. Collan, R. Fullér, and J. Mezei, "A fuzzy pay-off method for real option valuation," Journal of Applied Mathematics and Decision Sciences, vol. 2009, Article ID 238196, 14 pages, 2009.

[20] M. Collan, The Pay-Off Method: Re-Inventing Investment Analysis, CreateSpace Inc., Charleston, NC, USA, 2012.

[21] C. Carlsson, R. Fullér, and J. Mezei, "A quantitative view on quasi fuzzy numbers," in Combining Experimentation and Theory, vol. 271 of Studies in Fuzziness and Soft Computing, pp. 225-236, Springer, Berlin, Germany, 2012.

[22] C. Carlsson and R. Fullér, Possibility for Decision: A Possibilistic Approach to Real Life Decisions, vol. 270 of Studies in Fuzziness and Soft Computing, Springer, Berlin, Germany, 2011.

[23] F. Hassanzadeh, M. Collan, and M. Modarres, "A practical R\&D selection model using fuzzy pay-off method," The International Journal of Advanced Manufacturing Technology, vol. 58, no. 1-4, pp. 227-236, 2012.

[24] M. Collan and M. Heikkilä, "Enhancing patent valuation with the pay-off method," Journal of Intellectual Property Rights, vol. 16, no. 5, pp. 377-384, 2011.

[25] M. Collan, "Valuation of industrial giga-investments: theory and practice," Fuzzy Economic Review, vol. 16, no. 1, pp. 21-37, 2011.

[26] D. Allenotor, A Fuzzy Real Option Model for Pricing Grid Compute Resources, University of Manitoba, Manitoba, Canada, 2011.

[27] S. Johnson, T. Taylor, and D. Ford, "Using system dynamics to extend real options use: insights from the oil \& gas industry," in Proceedings of the International System Dynamics Conference, pp. 23-27, Nijmegen, The Netherlands, 2006.

[28] B. O'Regan and R. Moles, “A system dynamics model of mining industry investment decisions within the context of environmental policy," Journal of Environmental Planning and Management, vol. 44, no. 2, pp. 245-262, 2001.

[29] P. Sontamino and C. Drebenstedt, "A prototype decision making tool of coal mine planning using system dynamics model," in Mine Planning and Equipment Selection, pp. 1475-1484, Springer, Berlin, Germany, 2014.

[30] B. Tan, E. G. Anderson Jr., J. S. Dyer, and G. G. Parker, "Evaluating system dynamics models of risky projects using decision trees: alternative energy projects as an illustrative example," System Dynamics Review, vol. 26, no. 1, pp. 1-17, 2010.

[31] M. Collan, "Thoughts about selected models for the valuation of real options," Acta Universitatis Palackianae Olomucensis. Facultas Rerum Naturalium. Mathematica, vol. 50, no. 2, pp. 512, 2011.

[32] M. Kozlova, M. Collan, and P. Luukka, "Comparing DatarMathews and fuzzy pay-off approaches to real option valuation," in Proceedings of the Real Option Workshop (ROW '15), pp. 2934, Lappeenranta, Finland, 2015.

[33] G. Favato, J. Cottingham, and N. Isachenkova, "Blending scenarios into real options: relevance of the pay-off method to management investment decisions," Journal of Finance and Accounting, vol. 3, pp. 12-17, 2015.

[34] S. Mathews, "Valuing risky projects with real options," Research Technology Management, vol. 52, no. 5, pp. 32-41, 2009.

[35] P. Lall, R. Lowe, K. Goebel, and W. Cooper, "Cost assessment for implementation of embedded prognostic health management for electronic systems," in Proceedings of the 13th InterSociety Conference on Thermal and Thermomechanical Phenomena in 
Electronic Systems (ITherm '12), pp. 487-497, IEEE, San Diego, Calif, USA, June 2012.

[36] M. Kozlova, Analyzing the Effects of the New Renewable Energy Policy in Russia on Investments Into Wind, Solar and Small Hydro Power, 2015.

[37] C. Carlsson and R. Fullér, "On possibilistic mean value and variance of fuzzy numbers," Fuzzy Sets and Systems, vol. 122, no. 2, pp. 315-326, 2001.

[38] D. Bednyagin and E. Gnansounou, "Real options valuation of fusion energy R\&D programme," Energy Policy, vol. 39, no. 1, pp. 116-130, 2011.

[39] F. Hassanzadeh, M. Collan, and M. Modarres, "A practical approach to R\&D portfolio selection using the fuzzy pay-off method," IEEE Transactions on Fuzzy Systems, vol. 20, no. 4, pp. 615-622, 2012.

[40] M. Kozlova, M. Collan, and P. Luukka, "Renewable energy in emerging economies: shortly analyzing the Russian incentive mechanisms for renewable energy investments," in Proceedings of the International Research Conference, GSOM Emerging Markets Conference: Business and Government Perspectives, St. Petersburg, Russia, October 2015.

[41] Government of Russian Federation, “28 May 2013 Decree \#449 on the mechanism of promoting the use of renewable energy in the wholesale market of electric energy and power," 2013.

[42] Government of Russian Federation, "28 May 2013 Resolution \#861-r on amendments being made to Resolution \#1-r 8.01.2009 on the main directions for the state policy to improve the energy efficiency of the electricity sector on the basis of renewable energy sources for the period up to 2020," 2013.

[43] A. Boute, "Promoting renewable energy through capacity markets: an analysis of the Russian support scheme," Energy Policy, vol. 46, pp. 68-77, 2012.

[44] E. Vasileva, S. Viljainen, P. Sulamaa, and D. Kuleshov, "RES support in Russia: impact on capacity and electricity market prices," Renewable Energy, vol. 76, pp. 82-90, 2015.

[45] International Finance Corporation, "Russia's New Capacitybased Renewable Energy Support Scheme. An Analysis of Decree No. 449," vol. 2015, 2013.

[46] M. Kozlova and M. Collan, "Modeling the effects of the new Russian capacity mechanism on renewable energy investments," Energy Policy, vol. 95, pp. 350-360, 2016. 


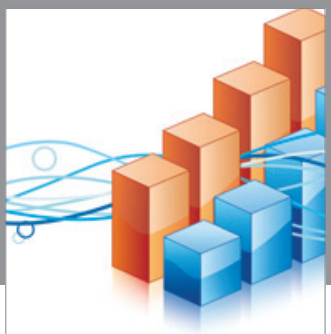

Advances in

Operations Research

vatem alat4

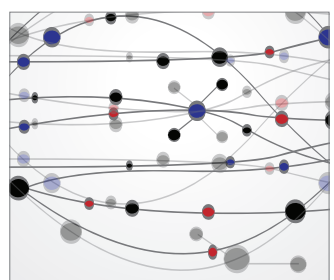

\section{The Scientific} World Journal
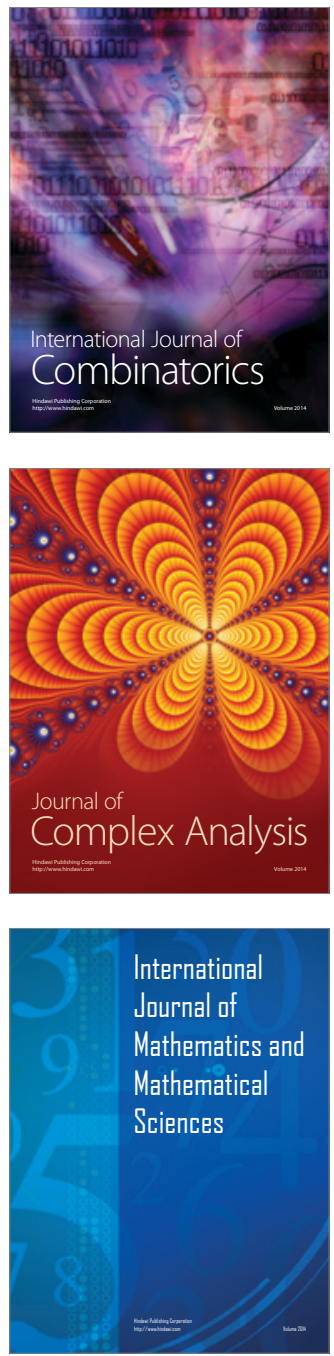
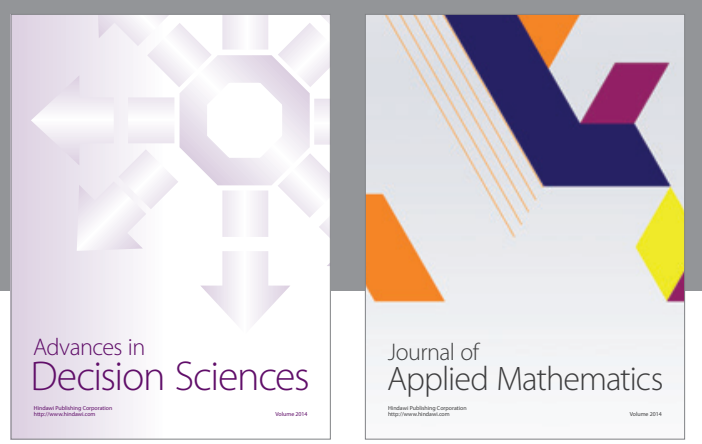

Algebra

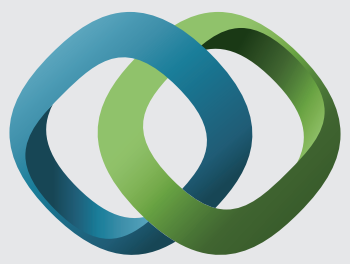

\section{Hindawi}

Submit your manuscripts at

http://www.hindawi.com
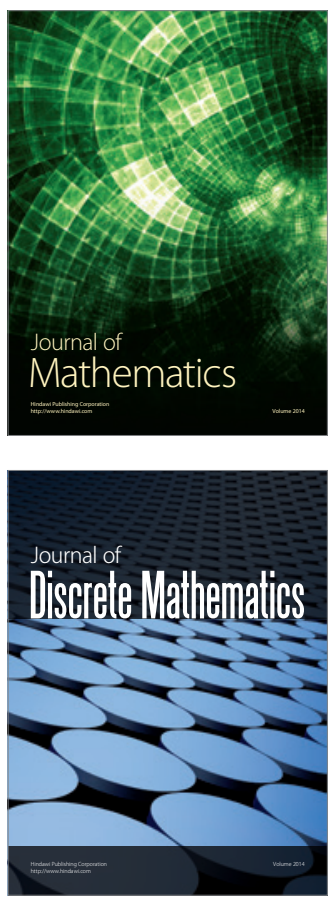

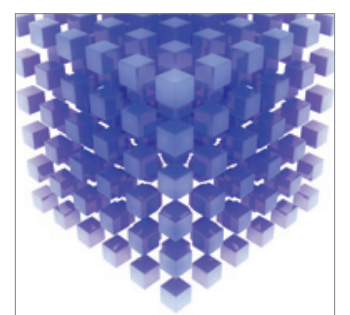

Mathematical Problems in Engineering
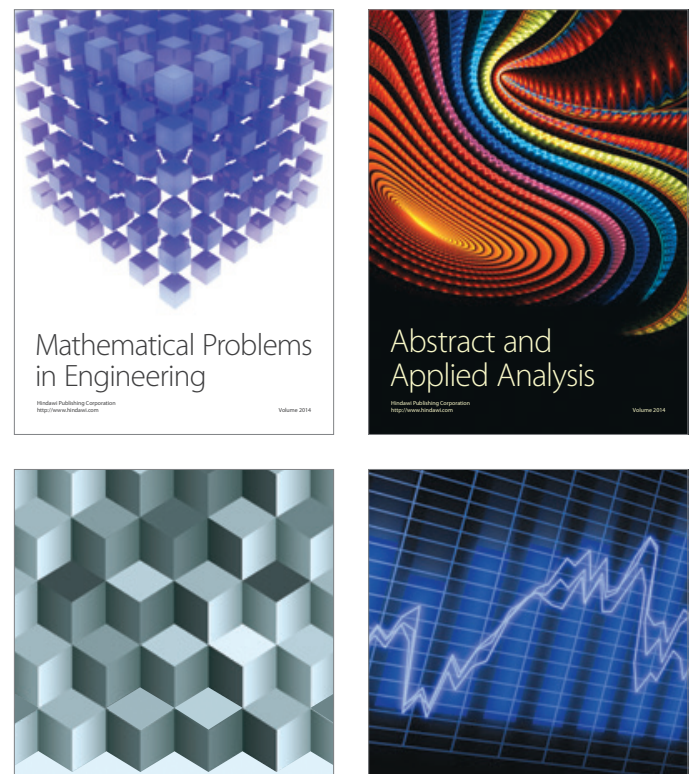

Journal of

Function Spaces

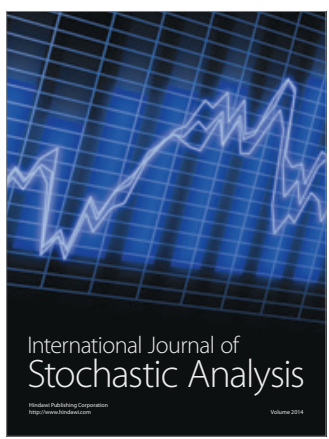

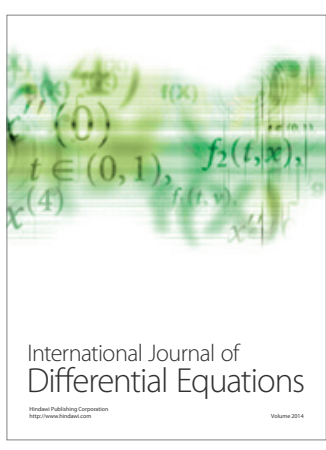
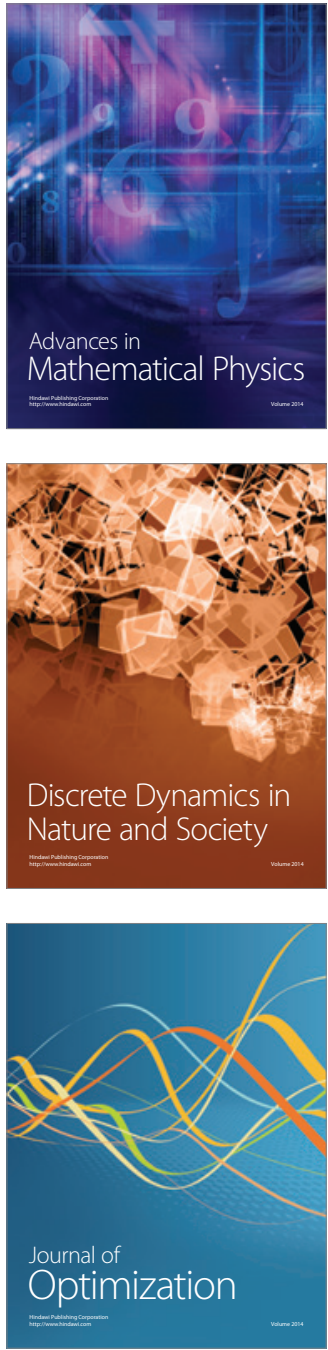